\title{
Effect of Cytidine Diphosphate Choline on Growth Hormone Secretion in Patients with Brain or Pituitary Lesions
}

\author{
Francesco SAlvadorini ${ }^{2}$, Paolo SABA ${ }^{2}$, Cesare Forli ${ }^{1}$, \\ Giorgio TUSINI ${ }^{1}$ AND Francesco GALEONE ${ }^{2}$ \\ Institute of Neurosurgery of University of Pisa ${ }^{1}$, Department of \\ Medicine of Psychiatric Hospital of Volterra ${ }^{2}$, Pisa, ITALY
}

\begin{abstract}
Plasma GH levels basally and after CDP-Choline $(300 \mathrm{mg})$ i.v. administration were evaluated by radioimmunoassay in patients with brain lesions variously located (frontal lobe, temporal lobe or hypothalamus) as well as in subjects with pituitary lesions. The results were statistically analyzed and compared with those obtained in normal subjects. A lack of response to CDP-Choline was observed in patients with pituitary adenomas or hypothalamic lesions. The $\mathrm{GH}$ response was delayed in patients with frontal lobe diseases. On the basis of the results obtained, we discuss the role of the different central nervous structures on the control of the GH activating system.
\end{abstract}

Many contributions have been made concerning the mechanism of regulation of the GH secreting system (Abrams et al., 1966; Boyd et al., 1970; Toivola et al., 1972; Giordano et al., 1973; Martin et al., 1973; Dunn and Arimura, 1974; Mc Intyre and Odell, 1974) but, at least as far as human beings are concerned, many doubts exist, both as to the identification of the nervous structures dealing with the control of the GH release and the specific origin of neurotransmitters with which they relate to the hypophysis. In fact at the present moment it is assured that the pituitary secretion of $\mathrm{GH}$ is regulated by stimulating (GH-RF) or inhibiting (GH-IF) hypothalamic factors (Deuben and Meites, 1964; Malacara et al., 1972; Brazeau et al., 1973).

There are no confirmed results concerning the type of neurotransmitters with which many and various extra-hypothalamic structures intervene to modulate the activity of the hypothalamic-hypophyseal $\mathrm{GH}$

Received February 20, 1979. secreting system. Therefore we consider of the following to be fundamental importance:- the dopaminergic mediation (Boyd et al., 1970), the adrenergic mediation (Blackard and Eidingsfelder, 1968) and finally the serotoninergic mediation (Yoshimura et al., 1973) at least in experimental conditions.

In this survey that we carried out, we aimed to explore and research the activity of the GH secreting system in pathological conditions of the central nervous system and the hypophysis, to contribute new knowledge, of the precise location of the nervous structures involved in the control of $\mathrm{GH}$ secretion in the human being.

In the patients on which we conducted our tests, we used CDP-choline, as an active agent for the release of $\mathrm{GH}$. The CDPcholine, a substance which in preceeding experiments by our group (Saba et al., 1975; Salvadorini et al., 1975) and more recently by others (Matsuoka et al., 1978), has been found efficient for the tests we conducted. 


\section{Materials and Methods}

Our survey was conducted on 42 subjects of both sexes. The group ranged in age from 6 to 70 rears (the average age being 41 years).

The group was divided into six smaller groups as shown in Table 1 . In the same table it is precisely shown, for every case, the age and the clinical diagnosis, confirmed by neuroradiological survey and by the various observations of the respective surgical interventions. Our survey included also a 16-yearold patient afflicted with pinealoma. No patients in groups 1, 2, 3 and 5 showed clinical or laboratory symptoms of hypopituitary function. The patients in group 4 were acromegalic while those in group 6 showed more or less evident signs of hypopituitarism.

In every specific case, we evaluated the effect brought on by CDP-choline $(300 \mathrm{mg}$ in $100 \mathrm{ml}$ of $0.9 \%$ salt solution administered i.v. for $30 \mathrm{~min}$ ) upon plasma GH; the blood samples were removed basally and after time intervals of $30,60,90,120$ and 150 min from the beginning of the test from an antecubital vein incannulated an hour prior to the start of the test and kept open with the help of a salt solution. The test was carried out at 0800 am with the patient recumbent in bed and fasting from at least $12 \mathrm{hrs}$ before.

GH level in blood samples was measured with the radioimmunoassay method according to Pennisi (1968).

The results obtained at the various times were compared with those obtained with the use of the paired $t$ statistical method. The absolute increase of $\mathrm{GH}$ obtained in the other various groups was compared with five healthy control subjects with the use of Student $t$ test.

\section{Results}

The results are given in Table II. The plasma GH level was an average in the normal limits in basal conditions in the patients of group I (subjects with anteriormiddle hypothalamic lesions) and in the subject afflicted by pinealoma. No modification occurred with the addition of CDPcholine. Only in one specific case afflicted by meningioma compressing the anterior hypothalamic structures there was an evident increase in $\mathrm{GH}$ up to $90 \mathrm{~min}$.

In the patients of group 2 (patients with temporal lobe lesions) plasma level of $\mathrm{GH}$ in basal condition was not too far from the normal level. After the use of CDP-choline there was an absolute increase between 14.5 and $39.3 \mathrm{ng} / \mathrm{m} l$ with a medium peak after $30 \mathrm{~min}$ then followed by a gradual decrease. The absolute increase was similar to that in normal control subjects.

In the patients of group 3 (patients with frontal lobe lesions) the plasma values were basally within the normal limits. After stimulation with the CDP-choline there was an increase in $\mathrm{GH}$ between 10.0 and 72.3 $\mathrm{ng} / \mathrm{m} l$ with a medium peak of $60 \mathrm{~min}$ with a gradual decrease to reach the $150 \mathrm{~min}$ levels which were significantly higher $(p<0.05)$ in comparison with the basal levels. Even in the patients of this group the absolute increase was similar to that in the normal control subjects.

In the patients in groups 4,5 and 6 we observed no significant average increase in plasma GH values after the pharmacological stimulus was applied. In fact in three patients of group 4 (acromegalic) and one patient of group 5 (cromophobe adenoma) we noted an evident response of $\mathrm{GH}$ to the CDP-choline.

\section{Discussion}

The results obtained in the patients subjected to our studies can be summed up as follows :

1) the $\mathrm{GH}$ response to the CDP-choline was abolished in patients with anterior and middle hypothalamic lesions as in those hypophysectomized and afflicted by chromophobe adenoma;

2) the stimulating effect of CDP-choline on plasma $\mathrm{GH}$ level appears to be partially abolished in the acromegalic subjects even though in some specific cases the response was definitely positive;

3 ) in the presence of lesions of the temporal lobe the response of GH to CDPcholine stimulating effect appears similar 
Table 1. Diagnosis for the cases investigated.

\begin{tabular}{|c|c|c|c|c|}
\hline \multicolumn{5}{|c|}{ Group 1. Hypothalamic lesions } \\
\hline 1) & Z. L. & $\hat{0}$ & 37 & \\
\hline 2) & C. F. & $\hat{\sigma}$ & 60 & "I \\
\hline 3) & B. L. & 우 & 25 & " \\
\hline 4) & G. S. & 우 & 18 & $" \prime$ \\
\hline 5) & M. A. M. & 우 & 29 & "I \\
\hline 6) & T. S. & 우 & 16 & \# \\
\hline 7) & B. P. & $\hat{0}$ & 14 & " \\
\hline 8) & L. A. & $\hat{0}$ & 6 & $" \prime$ \\
\hline 9) & G. L. & 우 & 54 & "I \\
\hline 10) & L. A. & $\hat{\delta}$ & 6 & $\prime \prime$ \\
\hline 11) & L. S. & $\hat{\delta}$ & 50 & " \\
\hline 12) & T. L. & 우 & 30 & \\
\hline
\end{tabular}

Group 2. Temporal lobe lesions

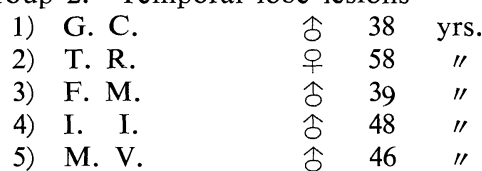
Angioma
Compressive meningioma
Parasellar cyst
Cyst of the 3 rd ventricle
Parasellar cyst
Basal meningioma
Sequelae of head injury
Neoplasma of the 3rd ventricle anterior wall
Suprasellar neoplasma
Neoplasma of the 3rd ventricle*
" " " " " anterior wall
Basal meningioma

Glioma
"
"
"

Unilateral glioma
1) G. M.
2) B. V.
3) B. L.
4) R. M.
5) G. A. M.
6) A. A.
B. S. E.

$\begin{array}{ccc}\text { 우 } & 42 & \text { yrs. } \\ \text { 京 } & 54 & \text { " } \\ \text { 全 } & 45 & \text { " } \\ \text { 合 } & 37 & \text { " } \\ \text { 우 } & 18 & \text { " } \\ \text { 令 } & 42 & \text { " } \\ \text { 우 } & 53 & \text { " }\end{array}$

Group 4. Pituitary lesions
1) A. D. R.
2) A. M
3) G. I.
4) A. F.
5) D. S.
6) D. S. A.
7) S. M. P.

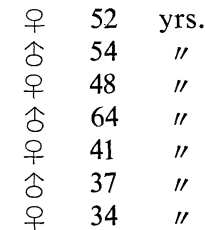

Group 5. Pituitary lesions
1) B. C.
2) B. A.
3) V. M. G.
4) G. G.
5) D. I. G.
6) P. B.
7) S. E.

$\begin{array}{ccc}\text { 옹 } & 25 & \text { yrs. } \\ \text { 우 } & 42 & \text { " } \\ \text { 우 } & 47 & \text { " } \\ \text { 옹 } & 65 & \text { " } \\ \text { 우 } & 53 & \text { " } \\ \text { 송 } & 56 & \text { " } \\ \text { 오 } & 70 & \text { " }\end{array}$

Group 6. Hypophysectomized
1) C. P.
2) P. G.
3) A. M.
4) V. M. L.

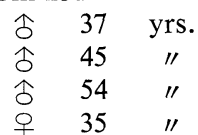
A. A.
今 16 yrs.
Pinealoma*

\footnotetext{
* Precocious puberty.
} 
Table 2. Plasma GH levels following CDP-choline injection.

\begin{tabular}{|c|c|c|c|c|c|c|c|c|c|}
\hline & & $0^{\prime}$ & $30^{\prime}$ & $60^{\prime}$ & $90^{\prime}$ & $120^{\prime}$ & $150^{\prime}$ & Peak & Increase \\
\hline \multicolumn{10}{|c|}{ Group 1.} \\
\hline 1) & Z. L. & $1.0^{*}$ & 1.1 & 1.2 & 1.3 & 1.0 & 1.0 & 1.3 & 0.3 \\
\hline 2) & C. F. & 6.0 & 10.5 & 10.0 & 19.0 & 15.0 & 14.0 & 19.0 & 13.0 \\
\hline 3) & B. L. & 1.8 & 2.5 & 2.1 & 1.0 & 1.0 & 1.0 & 2.5 & 0.7 \\
\hline 4) & G. S. & 9.0 & 6.6 & 9.0 & 9.0 & 11.4 & 9.9 & 11.4 & 2.4 \\
\hline 5) & M. A. M. & 1.0 & 1.0 & 1.1 & 1.7 & 1.8 & 1.1 & 1.8 & 0.8 \\
\hline 6) & T. S. & 15.0 & 15.0 & 20.0 & 20.0 & 15.0 & 16.0 & 20.0 & 5.0 \\
\hline 7) & B. P. & 2.4 & 7.0 & 7.0 & 6.0 & 9.0 & 8.5 & 9.0 & 6.6 \\
\hline 8) & L. A. & 4.2 & 4.2 & 4.5 & 6.0 & 3.9 & 3.6 & 6.0 & 1.8 \\
\hline 9) & G. L. & 1.2 & 0.6 & 0.0 & 0.0 & 0.0 & 0.0 & 0.0 & 0.0 \\
\hline 10) & L. A. & 1.9 & 2.3 & 2.6 & 2.5 & 2.6 & 4.1 & 4.1 & 2.2 \\
\hline 11) & L. S. & 1.5 & 3.5 & 3.1 & 1.2 & 1.2 & 1.3 & 3.5 & 2.0 \\
\hline \multirow[t]{4}{*}{ 12) } & T. L. & 0.9 & 1.8 & 2.1 & 3.5 & 3.5 & 3.9 & 3.9 & 3.0 \\
\hline & M.V. \pm & 3.82 & 4.67 & 5.22 & 5.93 & 5.45 & 5.36 & 6.87 & $3.15 \S \S$ \\
\hline & S.E.M. & 1.24 & 1.27 & 1.63 & 1.98 & 1.62 & 1.57 & 1.94 & 1.04 \\
\hline & & & N.S. & N.S. & N.S. & N.S. & N.S. & $\mathrm{p}<0.01$ & \\
\hline \multicolumn{10}{|c|}{ Group 2.} \\
\hline 1) & G. C. & 0.5 & 15.0 & 15.0 & 6.9 & 3.0 & 0.5 & 15.0 & 14.5 \\
\hline 2) & T. R. & 1.7 & 41.0 & 24.0 & 23.0 & 11.0 & 1.0 & 41.0 & 39.3 \\
\hline 3) & F. M. & 1.4 & 17.0 & 17.0 & 9.0 & 6.0 & 7.0 & 17.0 & 15.6 \\
\hline 4) & I. I. & 2.0 & 21.0 & 18.0 & 8.0 & 5.0 & 2.5 & 21.0 & 19.0 \\
\hline \multirow[t]{4}{*}{ 5) } & M. V. & 5.0 & 26.0 & 20.0 & 11.0 & 7.0 & 3.0 & 26.0 & 21.0 \\
\hline & M.V. \pm & 2.12 & 24.0 & 18.0 & 11.58 & 6.86 & 2.8 & 24.0 & $21.88 \S$ \\
\hline & S.E.M. & 0.85 & 4.55 & 1.71 & 3.27 & 0.64 & 1.28 & 4.55 & 5.04 \\
\hline & & & $\mathrm{p}<0.001$ & $\mathrm{p}<0.001$ & $\mathrm{p}<0.02$ & $\mathrm{p}<0.01$ & N.S. & $\mathrm{p}<0.001$ & \\
\hline \multicolumn{10}{|c|}{ Group 3.} \\
\hline 1) & G. M. & 0.7 & 13.0 & 73.0 & 36.0 & 22.0 & 15.0 & 73.0 & 72.3 \\
\hline 2) & B. V. & 1.2 & 41.0 & 58.0 & 41.0 & 27.0 & 12.6 & 34.0 & 31.0 \\
\hline 3) & B. L. & 1.2 & 7.0 & 23.0 & 13.0 & 11.0 & 5.0 & 23.0 & 21.8 \\
\hline 4) & R. M. & 3.0 & 17.4 & 34.0 & 33.0 & 27.0 & 12.6 & 34.0 & 31.0 \\
\hline 5) & G. A. M. & 5.0 & 8.7 & 15.0 & 15.0 & 9.0 & 1.2 & 15.0 & 10.0 \\
\hline 6) & A. A. & 0.9 & 6.0 & 30.0 & 24.0 & 29.0 & 12.0 & 30.0 & 29.1 \\
\hline \multirow[t]{4}{*}{ 7) } & B. S. E. & 17.0 & 23.0 & 27.0 & 15.0 & 21.0 & 18.0 & 27.0 & 10.0 \\
\hline & M.V. \pm & 4.14 & 16.58 & 37.14 & 25.28 & 20.86 & 11.9 & 37.14 & $33.0 \S$ \\
\hline & S.E.M. & 2.4 & 5.06 & 8.49 & 4.68 & 3.26 & 2.73 & 8.49 & 9.59 \\
\hline & & & $\mathrm{p}<0.05$ & $\mathrm{p}<0.01$ & $\mathrm{p}<0.001$ & $\mathrm{p}<0.001$ & $\mathrm{p}<0.05$ & $\mathrm{p}<0.01$ & \\
\hline \multicolumn{10}{|c|}{ Group 4.} \\
\hline 1) & A. D. R. & 27.0 & 60.0 & 55.0 & 80.0 & 90.0 & 40.0 & 90.0 & 63.0 \\
\hline 2) & A. M. & 3.0 & 79.0 & 39.0 & 13.0 & 11.0 & 2.5 & 79.0 & 76.0 \\
\hline 3) & G. I. & 3.3 & 4.5 & 6.4 & 3.9 & 3.2 & 2.7 & 6.4 & 3.1 \\
\hline 4) & A. F. & 38.2 & 33.0 & 33.0 & 33.5 & 38.2 & 35.0 & 38.2 & 0.0 \\
\hline 5) & D. S. & 15.0 & 18.6 & 39.0 & 52.0 & 32.0 & 20.0 & 53.0 & 37.0 \\
\hline 6) & D. S. A. & 15.3 & 13.5 & 10.2 & 20.4 & 20.4 & 10.5 & 20.4 & 5.1 \\
\hline \multirow[t]{4}{*}{ 7) } & S. M. P. & 0.0 & 1.3 & 3.6 & 12.7 & 12.0 & 5.1 & 12.7 & 12.7 \\
\hline & M.V. \pm & 14.54 & 29.98 & 26.6 & 30.78 & 29.54 & 16.54 & 42.67 & $28.12 \S$ \\
\hline & S.E.M. & 5.76 & 12.04 & 8.13 & 11.04 & 12.02 & 6.39 & 13.36 & 12.71 \\
\hline & & & N.S. & N.S. & N.S. & N.S. & N.S. & N.S. & \\
\hline \multicolumn{10}{|c|}{ Group 5.} \\
\hline 1) & B. C. & 1.8 & 1.5 & 2.1 & 1.0 & 1.0 & 1.0 & 2.1 & 0.3 \\
\hline 2) & B. A. & 6.9 & 9.0 & 14.0 & 10.0 & 11.0 & 1.7 & 14.0 & 7.1 \\
\hline 3) & V. M. G. & 4.0 & 6.0 & 5.9 & 10.0 & 17.1 & 10.1 & 17.1 & 13.1 \\
\hline 4) & G. G. & 1.2 & 1.3 & 0.6 & 1.2 & 0.4 & 0.0 & 1.3 & 0.1 \\
\hline 5) & D. I. G. & 0.0 & 0.4 & 0.0 & 0.0 & 0.0 & 0.0 & 0.4 & 0.4 \\
\hline 6) & P. B. & 3.6 & 5.4 & 3.6 & 3.9 & 5.3 & 0.6 & 5.4 & 1.8 \\
\hline
\end{tabular}




\begin{tabular}{|c|c|c|c|c|c|c|c|c|c|}
\hline & & $0^{\prime}$ & $30^{\prime}$ & $60^{\prime}$ & $90^{\prime}$ & $120^{\prime}$ & $150^{\prime}$ & Peak & Increase \\
\hline \multirow[t]{4}{*}{ 7) } & S. E. & 2.3 & 3.0 & 3.3 & 3.6 & 2.1 & 3.6 & 3.6 & 1.3 \\
\hline & M.V. \pm & 2.82 & 3.8 & 4.21 & 4.25 & 5.27 & 2.42 & 6.27 & $3.4 \S \S$ \\
\hline & S.E.M. & 0.92 & 1.27 & 1.94 & 1.7 & 2.65 & 1.47 & 2.7 & 2.0 \\
\hline & & & N.S. & N.S. & N.S. & N.S. & N.S. & N.S. & \\
\hline \multicolumn{10}{|c|}{ Group 6.} \\
\hline 1) & C. P. & 1.8 & 6.9 & 6.0 & 5.1 & 1.8 & 1.5 & 6.9 & 5.1 \\
\hline 2) & P. G. & 8.0 & 6.0 & 4.0 & 4.5 & 4.5 & 4.0 & 8.0 & 0.0 \\
\hline 3) & A. M. & 0.0 & 0.6 & 1.8 & 7.5 & 11.1 & 5.4 & 11.1 & 11.1 \\
\hline \multirow[t]{4}{*}{ 4) } & V. M. L. & 3.2 & 11.3 & 2.3 & 2.3 & 2.3 & 2.0 & 11.3 & 8.1 \\
\hline & M.V.土 & 3.3 & 6.17 & 3.52 & 4.85 & 4.92 & 3.22 & 9.32 & $6.07 \S \S$ \\
\hline & S.E.M. & 1.9 & 2.56 & 1.097 & 1.234 & 2.471 & 1.047 & 1.277 & 2.73 \\
\hline & & & N.S. & N.S. & N.S. & N.S. & N.S. & N.S. & \\
\hline & A. A. & 0.75 & 3.0 & 3.6 & 1.2 & 0.5 & 0.5 & & \\
\hline \multicolumn{10}{|c|}{ Controls } \\
\hline & 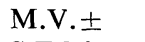 & 4.0 & 45.8 & 27.0 & 21.3 & 14.4 & 7.94 & 45.8 & 41.8 \\
\hline & S.E.M. & 1.1 & 9.35 & 6.75 & 5.2 & 3.75 & 0.98 & 9.35 & 9.45 \\
\hline & & & $\mathrm{p}<0.01$ & $\mathrm{p}<0.01$ & $\mathrm{p}<0.01$ & $\mathrm{p}<0.02$ & $\mathrm{p}<0.02$ & $\mathrm{p}<0.02$ & \\
\hline
\end{tabular}

* GH ng/ml.

Significativity of the absolute increase in the groups versus controls:

$\S$ N.S. $\quad \S \S \mathrm{p}<0.001$.

to those in the normal control subjects;

4) in the patients with frontal lobe lesions, even with a strong $\mathrm{GH}$ activating system, after the pharmacological stimulus, the response pattern appears abnormal, as it is delayed compared with normal subjects ;

5 ) in the patient afflicted by pinealoma we observed no response of GH to the CDPcholine.

The analysis of the data obtained suggests various considerations. From the pharmacological standpoint it becomes evident that the effect of CDP-choline appears on the adenohypophysis through the hypothalamic structures. Whereas it in fact failed in pathological conditions both in the hypothalamus and hypophysis. Actually it is impossible to determine the mechanism responsible for the action of CDP-choline in reference to the release of GH. It has been thought that the stimulating effect could be realized through the stimulation of the dopaminergic mediation (Saba et al., 1975 ; Salvadorini et al., 1975; Matsuoka et al., 1978) from the moment that on an experimental basis the CDP-choline action induces an increase in the cerebral content of dopamine through a stimulation of the biosynthesis carried out in the substantia nigra (Kobayashi, 1972). This action explains the efficiency of CDP-choline in the treatment of Parkinson's disease (Manaka et al., 1974) where the activity of the dopaminergic system remains deficient (Ehringer and Hornykiewicz, 1960). A possible mechanism of the stimulating activity of $\mathrm{GH}$ secretion based on activation of the dopaminergic system has been confirmed from observations of altered responses of $\mathrm{GH}$ to CDP-choline in conditions of chronic psychopatologia (Salvadorini et al., 1976). In these patients the dopaminergic system was found to not function properly (Kety et al., 1974; Lereboullet et al., 1975), although this sort of possible action of the CDP-choline does not coincide with the effects we observed in the acromegalic subjects, where very often, active dopaminergic agents like L-dopa, decrease the secretion 
of GH (Hoyte and Martin, 1975; Molinatti et al., 1976). The inhibitory effect on the PRL secreting system basally (Matsuoka et al., 1978) or after stimulation with sulpiride (Salvadorini et al., 1978) appears to confirm the stimulating effect of CDP-choline on the dopaminergic mediation. We therefore cannot exclude the possibility that the effect of the CDP-choline on GH was induced by other more general activation of nervous structures because CDP-choline is known to stimulate multiple enzimatic activity (Shimamoto and Arakami, 1975) through a generic series of phenomena of the phospholipid biogenesis.

Concerning the physiopathologic aspects of $\mathrm{GH}$ secreting system, our results indicate that even in the human being an important step in the activating process for the release of $\mathrm{GH}$ is represented by the basal hypothalamus in accordance with the data obtained in laboratory animals (Brown et al., 1971; Muller et al., 1971; Dunn and Arimura, 1974). Minor importance is given, regarding the neural control of $\mathrm{GH}$ secretion, to the temporal and frontal structures, even if these last ones would intervene and modulate the sensibility of the GH-secreting system toward different stimuli. If then the observation concerning the patient afflicted by pinealoma were confirmed, it could even be attributed to the posterior nervous structures, a function in the regulation of $\mathrm{GH}$ production.

But beyond any other pharmacological and physiological consideration, the results obtained in the present survey, show clearly that the study of the activation of the GH-secreting system by CDP-choline is particularly useful in order to assure the hypothalamic involvement in case of intracranial lesions.

\section{Acknowledgement}

The authors wish to thank Mr. Mauro Fausti for his skilled technical assistance and the CyanamidLederle for supplying the CDP-choline (Nicholin ${ }^{\circledR}$ ).

\section{References}

Abrams, R. L., M. L. Parker, S. Blanco, S. Reichlin and W. H. Daughday (1966). Endocrinology 78, 605.

Blackard, W. G. and S. A. Eidingsfelder (1968). J. Clin. Invest. 47, 1400.

Boyd, A. E., H. E. Lebovitz and J. R. Pfeiffer (1970). New Engl. J. Med. 283, 1425.

Brown, G. M., D. S. Schalch and S. Reichlin (1971). Endocrinology 88, 956.

Brazeau, P., W. Vale, R. Burgos, N. Ling, M. Butcher, J. Rivier and R. Guillemin (1973). Science 179, 77.

Deuben, R. R. and J. Meites (1964). Endocrinology $74,408$.

Dunn, J. and A. Arimura (1974). Neuroendocrinology $15,189$.

Eddy, R. L., A. L. Jones, Z. H. Chakmakjian and M. C. Silverthorne (1971). J. Clin. Endocrinel. Metab. 33, 709.

Ehringer, H. and O. Hornykiewicz (1960). Klin. Wochenschr. 38, 1236.

Giordano, G., M. Marugo, F. Minuto, T. Barreca and E. Foppiani (1973). Folia Endocrinol. 26, 523.

Kobayashi, T. Personal comunication to S. Manaka referred in S. Manaka, T. Fuchinoue, H. Sekino and K. Sano (1972). Brain Nerve (Tokyo) 24, 1051. (In Japanese)

Hoyte, K. M. and J. B. Martin (1975). J. Clin. Endocrinol. Metab. 41, 656.

Kety, S. I., D. Rosenthal, P. H. Wender, F. Schulsinger and B. Jacobsen. Genetics and Psychopathology (edited by R. Fieve, H. Brill and D. Rosenthal). John Hopkins Press, Baltimore (1974).

Lereboullet, J., A. Rosa and R. Olivier-Martin (1975). Rev. Prat. (Paris) 25, 1235.

Malacara, J. M., R. C. Valverde and S. Reichlin (1972) Endocrinology 91, 1189.

Manaka, S., T. Fuchinoue, H. Sekino and K. Sano (1972). Brain and Nerve 24, 1051. (In Japanese)

Manaka, S., K. Sano, T. Fuchinoue and H. Sekino (1974). Experientia 30, 179.

Martin, J. B., J. Kunter and P. Head (1973). Endocrinology 92, 1354.

Martin, J. B., L. P. Renaud and P. Brazeau Jr. (1974). Science 186, 538.

Matsuoka, T., M. Kawanaka and K. Nakai (1978). Endocrinol. Japon. 25, 55.

Mc Intyre, H. B. and W. D. Odell (1974). Neuroendocrinology $16,8$. 
Molinatti, G. M, F. Camanni, F. Massara, L. Belforte and A. Rosatello (1976). Min. Endocrinol. (Torino) 1, 55.

Muller, E. E., D. Miedico, G. Giustina, A. Pecile, D. Cocchi and V. Mandelli (1971). Endocrinology 89, 56.

Pennisi, F. (1968). J. Nucl. Biol. Med. 12, 137.

Saba, P., F. Salvadorini, F. Galeone, G. Tognetti and G. C. Saba (1975). Cl. Terap. (Rome) 74, 425.

Salvadorini, F., F. Galeone, M. Nicotera, M. Ombrato and P. Saba (1975). Curr. Ther. Res. (Tenafly) $18,513$.
Salvadorini, F., F. Galeone, V. Marescotti and P. Saba (1976). Proc. XVI Congr. Soc. Italian Endocrinol. (Bari) C. 38.

Salvadorini, F., F. Galeone, V. Marescotti and P. Saba (1978). Proc. XVII Congr. Soc. Italian Endocrinol. (Torino/Saint Vincent) C. 35.

Shimamoto, K., Y. Aramaki (1975). J. Takeda Res. Lab. 34, 189.

Toivola, P. T. K., C. C. Gale and C. S. Goodner (1972). Hormones 3, 193.

Yoshimura, M., Y. Ochi, T. Miyazaki, K. Shomi and T. Hachiya (1973). Endocrinol. Japon. 20, 135. 